\title{
Notes
}

\section{Update on Consumers' Preferences for Chestnuts}

\author{
Michael A. Gold ${ }^{1}$, Mihaela M. Cernusca, and Larry D. Godsey
}

AdDitionAL INDEX WORDs. marketing study, survey, demand, consumption, value added products

\section{$\mathrm{T}$} The University of Missouri (MU) held the second Missouri Chestnut Roast Festival on 16 Oct. 2004, with the primary objective of increasing domestic demand and consumption of chestnuts (Castanea spp.). The event attracted an increased number of visitors (3000 visitors in 2004 compared to 1000 in 2003 ) to New Franklin, Mo., the location of MU's Horticulture and Agroforestry Research Center. The festival was organized to expose the general public to chestnuts by offering samples of fresh and roasted chestnuts as well as value added products and cooking demonstrations. This event also provided information that continues a marketing study begun in 2003 with the objectives of assessing the consumer familiarity with chestnuts, pecans (Carya illinoensis), and eastern black walnuts (Juglans nigra) (Gold et al., 2004). In 2004 the survey focus was solely on chestnuts with 2003 results for chestnuts used as a benchmark.

\section{Materials and methods}

Data were collected based on a survey questionnaire administered to festival participants during the 2004 Missouri Chestnut Roast. The first survey question asked participants if they attended the previous year's festival. Other questions addressed the frequency of consumption, familiarity with cooking/preparing, interest in buying and consuming, attributes

University of Missouri, Department of Forestry, 203 ABNR Bldg., Columbia, MO 65211.

${ }^{1}$ E-mail address: goldm@missouri.edu that influence purchase decisions, and interest in obtaining more information, all focused on chestnuts. Using SPSS (SPSS Inc., Chicago), cross tabulation and frequencies distribution were used to analyze collected data.

\section{Results and discussion}

DEMOgRaphic CHARACTERISTICS OF SURVEY RESPONDENTS. The largest segment of respondents, $23 \%$, was represented by people between 46 and 55 years old, followed by people between 26 and 35 years (19\%), 36 to 45 years and over 65 years (18\%), 56 to 65 years $(16 \%)$, and $6 \%$ under 25 years. The majority of participants were well educated (college or masters / PhD $76 \%$ ). The remaining $24 \%$ had a high school (16\%) or technical school education. Three percent of participants were full-time farmers, $7 \%$ part-time farmers, and $13 \%$ acreage owners. The other participants had a variety of professions, such as retired $(23 \%)$, student $(20 \%)$, and professor/teacher (9\%). Twentysix percent of respondents had a total family income less than $\$ 35,000 ; 27 \%$ between $\$ 35,000$ and $\$ 49,999 ; 27 \%$ between $\$ 50,000$ and $\$ 74,999 ; 16 \%$ between $\$ 75,000$ and $\$ 99,999$; and $4 \%$ more than $\$ 100,000$. Compared with the demographic characteristics of Missouri, the following population segments were overrepresented: people over 55 years ( $34 \%$ for our sample vs. $23 \%$ for Missouri population); household income between $\$ 35,000$ and $\$ 99,000$ (70\% for our sample compared with $46 \%$ for Missouri population); and higher education-more than high school ( $76 \%$ vs. $32 \%)$.
FAMILIARITY WITH CHESTNUTS. In 2004, there were 213 questionnaires collected and analyzed. Considering the population of festival participants (about 3000), this sample produces $+/-6 \%$ sample error for a $95 \%$ confidence level(Dillman, 2000). This compares with 232 questionnaires collected and analyzed in 2003 . The decrease in responses (in spite of much larger attendance in 2004) can be attributed to the exclusive focus on chestnuts. This focus made respondents more reluctant to participate because chestnut is a product that they do not know very much about and thus many refused to fill out the questionnaire.

Of the sample surveyed, $13 \%$ were return visitors. Compared with the 2003 survey (Table 1), the number of people that have never consumed chestnuts in 2004 decreased from $67 \%$ to $46 \%$ ( or $67 \%$ to $53 \%$ if we remove the number of repeat visitors from 2003). This may be due to the increased number of people of European and Asian descent that participated in the second year of the Chestnut Roast, drawn to the event because of the chestnuts, word-of-mouth, and due to a better promotion of the event (which was advertised on the MU campus where international students, professors, and researchers are located). In 2004, 28\% of respondents consume chestnuts rarely [less than once per year (i.e., perhaps once every few years) ] and $18 \%$ once per year. In $2003,19 \%$ consumed them once per year (the "rarely" option did not exist in the 2003 survey). The majority ( $74 \%$ or 20 people) of the return visitors in 2004 consume chestnuts rarely or once per year. For most of the return visitors, the Chestnut Festival was the only occasion on which they consumed chestnuts. Of the first-time visitors, $54 \%$ had never tried a chestnut before and $26 \%$ consumed them rarely.

Although most participants were unfamiliar with chestnuts, they were enthusiastic about future consumption. Twenty-five percent of respondents declared that they would like to consume chestnuts monthly or more often (if available and affordable) and 39\% about two to six times per year. Only $12 \%$ of respondents preferred to consume chestnuts rarely and $4 \%$ never.

In 2003, familiarity with cooking/preparing chestnuts was very low (74\% not at all familiar). In 2004, two questions assessed this aspect: 
Table 1. Summary of results of surveys distributed during two Chestnut Roast Festivals (2003 and 2004) organized in New Franklin, Mo., to assess consumer preferences for chestnuts.

\begin{tabular}{lcc}
$\begin{array}{l}\text { Familiarity with chestnuts, attributes that influence } \\
\text { purchase of chestnuts, and basic knowledge about chestnuts }\end{array}$ & $\begin{array}{c}2003 \\
(\mathbf{N}=232)\end{array}$ & $\begin{array}{c}2004 \\
(\mathbf{N}=\mathbf{2 1 3})\end{array}$ \\
\hline & & \\
Familiarity with chestnuts & 67 & 46 \\
$\quad$ Percentage of people that have never consumed chestnuts & 19 & 46 \\
Percentage of people that consume chestnuts once per year & & \\
Attributes that strongly and very strongly influence purchase \\
of chestnuts
\end{tabular}

${ }^{2}$ Question was not offered in survey.

familiarity with roasting chestnuts and familiarity with preparing chestnuts using recipes. The results indicate that although the level of familiarity with any kind of cooking is low (71\% not at all familiar with cooking and 58\% not at all familiar with roasting), people are a little more familiar with roasting (12\% familiar and very familiar) than preparing chestnuts using recipes ( $5 \%$ familiar and very familiar). This may be attributed to the fact that roasted chestnuts were offered free during the event or people at least had heard of "chestnuts roasting on an open fire."

INTEREST IN BUYING CHESTNUTS. In 2003, preferences for buying or consuming chestnuts were explored. The highest preference was expressed for consuming chestnuts as part of a meal in restaurants $(46 \%$ interested and very interested) followed by buying them in a semi-prepared form in grocery stores (36\% interested and very interested) and by purchasing them in raw form from farmers' markets $(26 \%$ interested and very interested) (Gold et al., 2004). In 2004, we offered more options for the source of buying chestnuts and the form in which chestnuts can be purchased. Out of all respondents, 36\% had previously purchased chestnuts. Responses from the 64\% of respondents that had never bought chestnuts should be considered a best guess because they would not have tried the variety of products that were presented for evaluation in the survey. That said, the highest preference was expressed for roasted chestnuts (32\%), something that all attendees had at least heard about. Other preferences were: fresh in shell packaged $(30 \%)$, fresh in shell bulk (21\%), vacuum packaged ready to eat (17\%), and chestnut honey (14\%). Canned chestnuts, frozen peeled, dried, soup mixes, or jellies were among the least preferred form of buying chestnuts. The results are similar to the findings the Midwest Nut Producers Council presented in their final research report conducted for the Federal State Marketing Improvement Program. The familiarity with roasted chestnuts was higher than familiarity with other value added products for all ethnic groups analyzed (Smith et al., 2004).

In contrast with the results obtained in 2003, only 9\% of 2004 respondents expressed a preference for consuming chestnuts as part of meals in restaurants. One explanation is that in 2003 we provided respondents with few response options. Because of their lack of experience with chestnuts, it seemed normal for respondents to prefer a meal prepared by professionals to buying raw chestnuts and cooking them. This year we offered many examples of the forms in which chestnuts could be purchased and it was easier for respondents to choose. Even with so many options offered,
$33 \%$ of respondents answered "I don't know," meaning that chestnuts are still an unknown product for many people and they have a hard time deciding in what form(s) to buy them.

In response to the preferred source of buying chestnuts, $53 \%$ of respondents preferred to buy from grocery stores, in all likelihood because it is convenient to buy them while grocery shopping. This result is in accordance with the general trends of consumer attitudes published by the Food Marketing Institute, in which consumers seek one-stop shopping (convenience) and speed (Food Marketing Institute, 2004).

Besides the $53 \%$ that prefer to buy from grocery stores, $50 \%$ of respondents prefer to buy chestnuts from farmers' markets, $19 \%$ directly from the farm, 16\% from health food stores, and $6 \%$ from an ethnic store while only $5 \%$ indicated a preference for consuming them in a restaurant (percentages do not add to 100 because respondents could check more than one option on this question). Participants' responses are supported by the results of the national study conducted by the Hartman Group (2000). According to this study, over $55 \%$ of all purchases of organic and natural products take place at the grocery store/supermarket, while only $11 \%$ of purchases are at health food stores and 9\% at natural food supermarkets.

Even though roasted chestnuts sold at street corners are very popular in Asia and Europe, New York, or Chicago, only 3\% of respondents prefer to buy them on the street. Many chestnut producers sell chestnuts on-line. However, only 3\% of respondents indicated an interest in buying chestnuts on-line.

Attributes that influence PURCHASE DECISION. In 2003, statistical analysis identified the attributes that influence decisions to purchase chestnuts. Descriptive analysis revealed that taste $(72 \%)$, quality $(69 \%)$, and nutrition-diet-health (55\%) are the most important attributes that impact the decision to buy chestnuts. Price was listed as the least important attribute (26\%) (Gold et al., 2004). Multiple linear regression analysis indicated that only quality was statistically significant for buying raw chestnuts from farmers' markets and grocery stores. Quality and nutrition-diet-health were both significant for buying prepared/semi- 
prepared products that contain chestnuts in farmers' markets and grocery stores (Gold et al., 2004).

Similar results were obtained for 2004 data. Quality (69\%) and nutrition-diet-health (54\%) remain the most important attributes that influence decisions to purchase chestnuts, and price remains least important $(33 \%)$ (Table 1).

A cross-tab analysis of 2004 data revealed significant relationships between the attribute locally grown and age of participants $\left[\chi^{2}(4)=23.53, P<\right.$ $0.001]$. Participants over age 45 tended to be influenced more favorably by the fact that the products are locally grown $(61 \%)$ than people between ages $36-45(47 \%)$ or people under age $35(22 \%)$. The analysis also revealed a significant relationship $\left[\chi^{2}(4)=25.67\right.$, $P<0.001]$ between price and age. Participants over age 46 tended to be less influenced by price when making purchase decisions (20\%), compared to people between ages 36-45 (40\%) or people under age $35(57 \%)$.

EsSENTIAL KNOWLEDGE: WHAT DO YOU KNOW ABOUT CHESTNUTS? The results in 2004 were similar to those obtained in 2003 (Table 1). Only 15\% knew that due to their high moisture content, chestnuts need to be cooled soon after harvest and kept refrigerated (to minimize water loss and decay incidence), $27 \%$ that chestnuts are low in fat, and $23 \%$ that chestnut flour is gluten free. Most of the respondents answered "I don't know" (59\% for need refrigeration, $63 \%$ for fat content, and $73 \%$ for gluten-free flour). Clearly much remains to be done in terms of educating the consumer about the health and nutritional benefits of chestnuts. The survey was a first step in educating consumers. Even though they did not know the answer, at least they were made aware that there is a relationship between chestnuts and refrigeration, fat content, and being gluten free.

\section{Conclusions/ recommendations}

Overall, results obtained in 2004 confirmed those obtained in 2003 and also provided additional information. As of 2004 consumers remain unfamiliar with chestnuts: they do not know about their healthful properties, in what form and where to buy them, or how to prepare them. Those participants that expressed an opinion prefer to buy roasted or fresh chestnuts from grocery stores or farmers' markets. Quality and nutrition-diet-health were perceived as the most important attributes that influence the decision to purchase chestnuts.

A national educational campaign will help to increase consumer awareness. More advertising of national chestnut week (the second full week of October) will provide additional promotion and help to increase awareness. Consumers and produce managers in grocery stores must be educated in handling and using chestnuts. Cooking demonstrations, samples, recipes, and information about health and nutritional benefits will help motivate consumers to try chestnuts and incorporate them into their regular diet.

\section{Literature cited}

Dillman, D.A. 2000. Mail and internet surveys. The tailored design method. 2nd ed. Wiley. New York.

Food Marketing Institute. 2004. Trends in the United States, consumer attitudes \& the supermarket. 3 Mar. 2005. <http://www. fmi.org/pub/summaries/ExecutiveSummary_Trends_2004.pdf>.

Gold, M., M.M. Cernusca, and L. Godsey. 2004. Consumer preferences for chestnuts, eastern black walnuts, and pecans. HortTechnology 14(4):583-589

Hartman Group. 2000. The organic consumer profile. A national study conducted by the Hartman Group. 3 Mar. 2005. <http://www.marketresearch. com/product/display.asp? productid $=5$ $84387 \&$ \&ID $=80558533-312689034$ 376338511 \&curr $=$ USD\&xs=r\&kw $=$ groc ery\%09stores\&view=abs $>$.

Smith, B., B.K. Behe, J.B. Harte, K. Dolan, D.F. Fulbright, J. Sowa, R.M. Walden, and M. Tan. 2004. Developing value-added chestnut products to increase grower profits. A final report on the research conducted for Federal State Mktg. Improvement Program. Midwest Nut Producers Council and Michigan State Univ. 3 Mar. 2005. <http://www.ams.usda.gov/tmd/FSMIP/FY2002/MI0365.pdf>. 